\title{
A SEXUALIDADE NO SISTEMA PRISIONAL: VISITA ÍNTIMA NO PRESÍDIO CENTRAL DE PORTO ALEGRE
}

\section{Dani Rudnicki* Ana Carolina da Luz Proença**}

RESUMO: O artigo aborda a sexualidade e a visita íntima no âmbito do sistema prisional. A partir de uma pesquisa qualitativa (entrevistas) com mulheres visitantes. Objetiva abordar a realidade do cotidiano que elas enfrentam, passando por inúmeras situações com o intuito de viver momentos com seus parceiros. Para tanto, é realizada uma reflexão sobre a sexualidade e importância da visita íntima no sistema, intentando discorrer sobre a relação entre as mulheres visitantes, seus companheiros e a instituição prisional. Por fim, conclui que a visita íntima é extremamente importante e transcende a questão sexual.

Palavras-chave: Direito penal; Prisão; Sexualidade; Visita íntima; Mulheres.

\section{SEXUALITY IN THE PRISON SYSTEM: AN INTIMATE VISIT TO THE CENTRAL PRISON IN PORTO ALEGRE}

\begin{abstract}
The article addresses sexuality and intimate visit within the prison system. From a qualitative research (interviews) with visiting women. It aims to address the everyday reality they face, going through numerous situations in order to live moments with their partners. To this end, a reflection is made on the sexuality and importance of intimate visits in the system, trying to discuss the relationship between visiting women, their partners and the prison institution. Finally, he concludes that the intimate visit is extremely important and transcends the sexual issue.
\end{abstract}

Keywords: Criminal Law; Prison; Sexuality; Intimate Visit; Women.

\section{Introdução}

Ainda que o sistema prisional brasileiro seja, em diversos aspectos, bastante discutido, essa sociedade possui questões "esquecidas" e que permanecem como objetos cheios de tabus e mistérios. Esses problemas são ignorados, também, pela academia, embora como outro qualquer, necessitam de pesquisa e discussão. O tema, em análise no presente artigo, é carente de pesquisa e, justamente por estar explícita a escassez de informações científicas sobre visita íntima,

\footnotetext{
* Mestre em Direito pela Universidade do Vale do Rio dos Sinos (1999) e Doutor em Sociologia pela Universidade Federal do Rio Grande do Sul (2007). Professor do PPG em Direito da Universidade La Salle/Canoas. E-mail: danirud@hotmail.com

${ }^{* *}$ Mestranda do programa de Pós-Graduação em Direito e Sociedade da Universidade La Salle/Canoas - Rio Grande do Sul. E-mail: anacarolinalproenca@gmail.com
} 
sexualidade e sexo, se faz necessário tal investigação, o que justifica a explanação sobre o assunto tratado aqui.

Para tanto, se faz imperioso um estudo fundamentado na "sociologia jurídico-penal", que visa estudar "[...] tanto as reações institucionais dos órgãos oficiais de controle social do desvio (consideradas, também, nos seus fatores condicionantes e nos seus efeitos) quanto as reações não institucionais" (Baratta, 2011, p. 24).

Atribui-se aqui, como perspectiva, entender as relações que se originam entre os estabelecimentos prisionais, presos e suas companheiras/esposas. Afinal, as prisões transformam vidas dentro e fora das grades. Logo, o presente artigo resulta da necessidade de problematizar a questão da sexualidade e das visitas íntimas.

O contato com os familiares e a possibilidade de visitas (íntimas) têm importante papel dentro do sistema prisional (Rudnicki e Santos, 2015; Rudnicki e Veeck, 2018); é o momento em que mães, companheiras, esposas, namoradas e filhos passam longas horas na fila de espera aguardando para entrar. Esse momento é tão importante que Moraes (2005, p. 251) revela, através do olhar de um agente penitenciário, existir quatro pontos contribuindo para a sustentação da paz na prisão: alimentação, assistência jurídica, saúde e visita (pode-se agregar um quinto: drogas lícitas e ilícitas).

Todos visitantes de presos são submetidos às exigências burocráticas da instituição prisional e procedimentos de revista. Ingressam em um lugar criado para punir, no qual as pessoas são "vomitadas" (Levi-Strauss, 1996, p. 366), ou seja, considerados seres humanos indesejados. E, junto com essas pessoas, seguem desejos, sonhos e vidas:

Penso em nossos costumes judiciários e penitenciários. Ao estudá-los de fora,
ficaríamos tentados a contrapor dois tipos de sociedades: as que praticam a
antropofagia, isto é, que enxergam na absorção de certos indivíduos detentores de forças
tremendas o único meio de neutralizá-las, e até de se beneficiarem delas; e as que, como
a nossa, adotam o que se poderia chamar de antropemia (do grego emein, "vomitar").
Colocadas diante do mesmo problema, elas escolheram a solução inversa, que consiste
em expulsar esses seres tremendos para fora do corpo social, mantendo-os temporária
ou definitivamente isolados, sem contato com a humanidade, em estabelecimentos
destinados a este fim.

As visitantes percorrem um trajeto, levando para seus companheiros, além de alimentos, informações processuais, esperança, amor, carinho, cuidado e sexo. Há mulheres que participam deste ritual por anos; sustentam as casas e educam os filhos sozinhas, sem abandonar seus parceiros que estão reclusos. E deve-se adicionar, à sua rotina viagens de ônibus, filas de espera e demorado ingresso nas instituições prisionais. 
Penitenciárias que se configuram em um território caracterizado pela violência, dor, tratamento desumano e controle. Permanece a crença de que o sistema prisional tem o dever de aniquilar com o indivíduo, punindo da forma mais severa possível.

Diante desse contexto, urge a necessidade de discutir sobre a relevância da sexualidade no âmbito prisional, partindo de um olhar crítico, jurídico e compreensivo, merecedor de proteção específica e fundamental para o entendimento do assunto abordado. Assim, esse artigo permite enxergar o significado da visita íntima do ponto de vista das mulheres visitantes procurando mostrar o impacto e a real importância na vida dos envolvidos.

Busca-se avançar na discussão abordando a importância que essas mulheres têm na vida dos apenados e também os benefícios trazidos por elas para o sistema prisional até mesmo como uma forma de diminuir o sentimento de rejeição de quem se encontra confinado.

Para tanto, se utiliza uma pesquisa qualitativa, com estudo de campo realizado na fila de visitantes do Presídio Central, atualmente chamado de Cadeia Pública de Porto Alegre (Decreto estadual n. 53.297 de 10 novembro de 2016).

Esse campo constitui em permanência de mais de três horas, entre às 05:56 e 09:18 horas da manhã, no dia sete de março de 2020. Oportunidade em que foi possível entrevistar seis mulheres.

O grupo pesquisado, com uma exceção, tem entre 20 e 24 anos. Na ocasião, todas mulheres disseram possuir documento comprobatório de casamento. Nenhuma se identificou como prostituta, embora se saiba que existam visitantes contratadas para fazer sexo.

A organização do artigo divide-se em um primeiro momento apresentando a questão da sexualidade vista como um direito fundamental para a dignidade da pessoa humana; nele, se desmistificam tabus que permeiam o assunto. Reforça-se a necessidade de refletir a sexualidade sem discursos opressores e limitadores; transcender o olhar biológico, necessitando reconhecer a sexualidade como um direito de todos, e também daqueles que estão privados de liberdade.

Após, reflete-se sobre como funciona a relação entre visitas, presos e sistema prisional; busca-se analisar o perfil e a importância das mulheres, tanto para o sistema prisional, quanto para o preso. Prosseguindo, aborda-se a questão da importância da visita íntima, analisando o contexto como fato social nas prisões na medida em que mulheres entram nos estabelecimentos prisionais para reforçar laços e prestar apoio afetivo como forma de amenizar o sofrimento dos apenados. 


\section{Sexualidade e Direito}

Hoje, a questão da sexualidade é observada como essencial para a existência; ou seja, imprescindível na vida do ser humano, considerando-se parte da ideia de dignidade da pessoa humana. Outrossim, é possível observar que a sexualidade é assunto complexo, além de ser alvo de preconceito.

Significa dizer que vislumbramos a sexualidade como busca de prazer, descobertas de sensações através do contato e toque, gerando atração por outras pessoas, do sexo oposto ou do mesmo sexo, com o intuito de obter a satisfação e, consequentemente, o contentamento pessoal dos seus desejos.

A obra clássica de Lemos Britto, escrita no século passado, vai em sentido contrário, estigmatizando a questão sexual quando menciona que o sexo é um problema, pois segundo ele, na mente de cada recluso encontra-se um símbolo feminino que se externaliza por meio de tatuagens sobre a pele; é a "obsessão sexual" que surge igualmente nos desenhos nas paredes das celas (Britto, 1934, p.28-32). Ele também afirma que é possível conectar a sexualidade aos crimes que povoam as prisões (Britto, 1934, p.33).

Ao contexto, cabe refletir que há efeitos a partir da negação institucional da dimensão sexual das pessoas que ali habitam. Esses impactos excedem aspectos do sexo biológico, da identidade de gênero, do comportamento sexual, das relações familiares, das relações de poder e da cultura do ambiente prisional, tudo vascolejado por um coquetel físico e psicológico constante e intenso de um confinamento extremamente árduo que contribui para um fervor intenso de ideias, desejos e fantasias.

E alerta, “A visita de uma representante do sexo frágil basta para alvoroçar toda uma prisão, para reacender incêndios que pareciam extintos [...] Nada perturba mais uma penitenciária que odôr di feminina” (Britto, 1934, p. 39). Por fim, sugere: “A sexualidade absorve todas as forças humanas; apenas a educação moral, que se estratificam no homem civilizado, promovem o equilíbrio instável em que ele vive” (Britto, 1934, p. 10).

Essa perspectiva existia desde antes: “[...] A condenação moral das práticas sexuais dos prisioneiros levou a, desde o século XIX, tentativas de controle e repressão. [...]” (Aymard; Lhuilier, 1997, p. 35). Mas os instintos, necessidades e desejos sobrepujaram essa perspectiva. A humanidade está presa "de uma imensa curiosidade pelo sexo, obstinados em questioná-lo, incansáveis a ouvi-lo e ouvir falar nele, prontos a inventar todos os anéis mágicos que possam forçar sua discrição" (Foucault, 2019, p. 85). 
Em muitas ocasiões, o tema ainda é tratado com discurso extremamente repressivo e punitivo. A maioria dos assuntos relacionados ao sexo é fruto de um equívoco associado apenas às relações sexuais. Consequência dos inúmeros preconceitos a respeito da sexualidade que deveria ser uma parte essencial da nossa vida, não cabendo ser tratada com desprezo e vergonha. Assim, em regra, na contemporaneidade, ele é aceito como importante dimensão da vida humana.

No âmbito prisional, depois de ser aceito, informalmente, nos pátios das prisões em dias de visita, escondido por barracas improvisadas de lençóis, passou a ser considerado direito do apenados e regulamentado.

De maneira sucinta e direcionada ao propósito deste trabalho, Carmargo e Pinhal (2018, p. 165) defendem que "uma das maneiras de definir a sexualidade é a busca por satisfação plena, em desenvolvimento contínuo, que envolve as questões biológicas, psicológicas e sociais".

Entender a sexualidade, em uma perspectiva multidisciplinar, sem restringir o olhar apenas ao biológico, levando inclusive em consideração a questão de gênero, tem sido cada vez mais necessário. Reforça a ideia de que “[...] uma sociedade, identidade, estrutura-se, mantém-se enquanto organização tendo a sexualidade como uma dimensão essencial do ser humano [...]" (Lago, Tarouco, Junior, 2016, p. 312). Portanto, “Em suma, trata-se de definir as estratégias de poder imanentes a essa vontade de saber. E, no caso, específico da sexualidade [...]" (Foucault, 2019, p. 83).

Infere-se, portanto, a necessidade de abordar a questão sexual sem "[...] a ideia de uma energia rebelde a subjugar [...]" (Foucault, 2019, p. 89). Logo, intenta-se falar da(s) sexualidade(s) levando em consideração a evolução das definições e comportamentos sexuais dos indivíduos ocorrida ao longo desses anos, reforçando que, apenas com pesquisa e diálogo, se acabará com os tabus que cercam o assunto.

Sendo a sexualidade, responsável por uma parcela que abrange o ser humano, a qual é responsável também por sua vida mental e psíquica, o sexo se torna um impulso que conduz o bem-estar e a satisfação. Isto posto, é possível enxergar a questão sexual como um bem imaterial, diretamente ligado a essência do indivíduo e fazendo imperioso mencionar a relação com a dignidade da pessoa humana.

Deve-se atentar que, no momento, não se possui a dignidade sexual reconhecida, porém, ela está intrinsecamente ligada à essência do ser humano, devendo ser respeitada e tratada com 
igualdade. Assegurando condições decentes de vida, se faz necessário o reconhecimento e respaldo desta garantia. Confirmando a conjuntura, Bassani (2016, p.27) salienta:

Amor, sexo e sexualidade. Temas intrigantes que tem sido foco de discursos científicos dos mais diversos campos, estabelecendo sua centralidade na formação do indivíduo moderno. No entanto, ao serem transpostas para o território carcerário estas palavras parecem embaraçar a visão. Difícil falar desses assuntos em um terreno fundado na violência e no controle.

Gelpi (2000, p. 163), na sua obra autobiográfica, escreve: “Clarão, memória, estupor: são seis anos que não vejo uma mulher pelada! Mulher mesmo, pelada de fato - em carne e osso, em perfume e graça. Sem meias, com meias de nylon: uma no chão, outra na beira da cama...”, sustentando a afirmação de que a sexualidade aflora ainda mais quando na condição de privação.

$\mathrm{O}$ assunto proposto ao contexto testemunha que "a prisão, local de execução da pena, é ao mesmo tempo, local de observação dos indivíduos punidos” (Foucault, 2019, p. 242). Faz-se necessário reconhecer "[...] o exercício da sexualidade como direito fundamental e buscando identificar os processos que parecem controlar, limitar e vigiar a sexualidade em contextos de privação de liberdade" (D’Angelo; Hernandez, 2017, p. 101), para então, decifrar os enigmas com o objetivo de enriquecer as pesquisas realizadas perante a sociedade.

\section{Prisão, sexo e visita íntima}

$\mathrm{O}$ artigo $1^{\circ}$ da Lei de Execução Penal (LEP) estabelece que "a execução penal tem por objetivo efetivar as disposições de sentença ou decisão criminal e proporcionar condições para a harmônica integração social do condenado e do internado", situação que não ocorre nos estabelecimentos do país (e do mundo, eis que embutido de um falso discurso ressocializador: Foucault, 2019). "Esse aspecto ambíguo em relação à possibilidade de ressocialização é somente mais uma das formas da manifestação da ambiguidade estrutural da prisão, expressa na questão sobre qual a função da prisão: punir ou ressocializar” (Moraes, 2005, p. 239).

Além disso, e da superlotação dos estabelecimentos, pode-se referir a crise no sistema penitenciário, devido a precariedade no tratamento oferecido aos envolvidos no sistema prisional, indo contra o direito assegurado na lei e ferindo, muitas vezes, a dignidade da pessoa humana, para quem está dentro e fora das grades. Reforçando tal premissa, o autor da obra “Criminologia Crítica e Crítica do Direito Penal”, menciona:

[...] os institutos de detenção produzem efeitos contrários à reeducação e à reinserção do condenado, e favoráveis à sua estável inserção na população criminosa. O cárcere é contrário a todo moderno ideal educativo, porque este promove a individualidade, o 
autorrespeito do indivíduo, alimentando pelo respeito que o educador tem dele". (Baratta, 2011, p. 183-184).

Tal situação permite dizer que "Essa marca atinge todos que nela ingressam, como detentos, funcionários, pesquisadores ou visitantes" (Rudnicki; Schafer e Silva, 2017, p. 612). Para o contexto prisional, "Punir é castigar, fazer sofrer. A intimidação a ser obtida pelo castigo demanda que este seja apto a causar terror. Ora, tais condições são reconhecidamente impeditivas de levar ao sucesso uma ação pedagógica.” (Thompson, 1988, p. 5).

Suponho que as divergências inconciliáveis entre as formas de vida, observadas dentro e fora dos muros, ficarão ainda mais realçadas ao estudarmos o sistema social da penitenciária. No momento, gostaria de anotar que, se adaptação à prisão não significa adaptação à vida livre, há fortes indícios de que a adaptação à prisão implica em desadaptação à vida livre." (Thompson, 1988, p.13).

Na reflexão de Thompson (1988, p. 57), “o muro da prisão, física e simbolicamente, separa duas populações distintas: a sociedade livre e a comunidade daqueles que foram, por ela, rejeitados", ou, lembre-se, vomita os apenados. Aqui, cabe lembrar que os fatos por vezes ignoram as regras, assim, na França, relações sexuais são proibidas, mas os agentes penitenciários fazem "vistas grossas" (AYMARD; LHUILIER, 1997, p. 75).

Logo, se faz imperioso um estudo para além dos muros da instituição prisional, visto que, “a prisão é uma experiência em família para muitas mulheres no Brasil [...]” (Queiroz 2019, p. 62), ou seja, a problemática transborda o espaço físico e permite observar vínculos, pessoas e histórias.

Sendo assim, tem-se que o direito à visita íntima é reflexo do princípio da dignidade humana mencionado no artigo $1^{\circ}$, III, da Constituição Federal de 1988. Não sendo possível afetar tal prerrogativa de maneira injustificada para não influenciar de modo negativo o indivíduo que um dia retornará ao convívio social.

Ademais, é válido enfatizar que o direito de receber visitas também está resguardado no artigo 41, inciso X, da Lei de Execução Penal, intensificando que "Constituem direito do preso: visita do cônjuge, da companheira, de parentes e amigos em dia determinados".

A inserção dos familiares para o interior da prisão pode ser percebida nas visitas às unidades penitenciárias, em que se destaca a presença massiva de mulheres:

Dentre as visitas, que em 2012 chegaram a 260.000 pessoas, cerca de $80 \%$ foram realizadas por mulheres. Policiais militares que atuam a longo tempo na Sala de Visitas 
atestam a grande presença de mães, mas informam que com o passar do tempo, estas tendem a ser substituídas pelas companheiras" (Bassani, 2016, p. 135).

Com atenção é possível ver o quanto a visita íntima se faz importante na vida dos "Confinados contra a vontade" (Thompson, 1988, p. 57); principalmente para a diminuição da tensão, violência, rejeição e sentimento de exclusão social.

Sobre o contexto, afirma-se que "Outra terrível privação, imposta pela penitenciária, refere-se à perda absoluta do direito à intimidade" (Thompson, 1988, p. 61). Ainda há quem pense que a prática sexual é um privilégio apenas para pessoas que estão fora dos muros que delimitam a liberdade. Ignorando a necessidade da prática sexual intramuros e inclusive utilizando o discurso de que o sexo deve ser considerado privilégio dentro da prisão.

Dentro desse contexto, inicia-se a pesquisa às $5 \mathrm{~h} 38$ da manhã do dia sete de março de 2020, sábado. A caminho do Presídio Central, o motorista do aplicativo questiona a razão do deslocamento para aquele lugar. Explica-se o motivo da ida e o assunto da pesquisa, posteriormente, ele relata que conhece bem a conjuntura, pois sua prima foi "mulher de traficante" e durante muito tempo visitou de forma semanal a instituição.

Informa que a familiar era tão "tinhosa" que comandava o tráfico para o companheiro enquanto ele estava preso. Falou que ela agenciava encontros para presos que faziam parte da "prefeitura da galeria"1 em troca de dinheiro, caracterizando a prostituição.

Referindo-se ao contexto de privilégios e normas que se oriunda no cárcere, Baratta (2011, p. 185-186) explica:

Em geral pode-se dizer que a adaptação a estas normas tende a interiorizar modelos exteriores de comportamento, que servem ao ordenado desenvolvimento da vida na instituição. Esta se torna o verdadeiro objetivo da instituição, enquanto a função propriamente educativa é amplamente excluída do processo de interiorização das normas, também no sentido de que a participação em atividades compreendidas diretamente nesta função ocorre com motivação estranha a ela, e de que é favorecida a formação de atitudes de passivo conformismo e de oportunismo.

Na chegada ao destino, às 5h56, encontram-se 48 mulheres na fila de entrada. Por um breve período, observa-se o local: a fila aumenta a cada minuto. Percebem-se apenas mulheres e todas estão vestidas de maneira simples. É fácil identificar as companheiras e esposas na medida em que é observado o cuidado delas com relação à maquiagem; muitas aproveitam o longo

1Cada galeria possui a sua "Prefeitura", que é composta pelo "prefeito" (pessoa que manda na galeria) e assessores. Ela é reconhecida pela administracão do presídio que a convoca quando necessário para informar os presos ou negociar com eles. 
momento na fila, para fazer/retocar a maquiagem como forma de agradar quem está na espera por elas.

A conjuntura permite lembrar do escrito de Souza (1978, p. 52) que, contextualizando a cidade-presídio (Carandiru), menciona:

\begin{abstract}
Para poder entrar às sete horas, muitas famílias de presos chegam aqui antes de uma hora da madrugada. Alguns com criança no colo, enfrentando frio ou chuva, brigando por um lugar na fila. Há uma tensão grande, provocada pelo nervosismo consequente dos problemas que causa a prisão de um chefe de família ou o desespero pela situação do filho preso uso de drogas.
\end{abstract}

Verifica-se que todas estão com chinelos, por ser determinação da instituição prisional. No Rio Grande do Sul, a Portaria 160/2014, da Susepe, estabelece o Regulamento Geral para ingresso de visitantes e materiais em Estabelecimentos Prisionais.

O documento tem o intuito de normatizar, orientar e padronizar os procedimentos gerais de visitação nos estabelecimentos prisionais do Estado. Consequentemente, o ingresso e permanência de visitantes deve respeitar as exigências impostas pelo regulamento mencionado.

Toda pessoa reclusa terá direito a no mínimo um e no máximo dois dias de visita por semana devendo ser considerado o padrão de comportamento do preso e as características do estabelecimento prisional para fazer jus ao benefício.

No Presídio Central, as visitas ocorrem da seguinte forma: terça, quarta, sábado e domingo das $7 \mathrm{~h} 30$ até às $17 \mathrm{~h}$ horas. Cada dia corresponde um grupo de visitantes vinculados a uma a galeria, assim evita-se que grupos rivais se cruzem nos corredores e estejam no apito no mesmo momento.

Com relação as mulheres que estão na condição de visitantes a orientação é de que não será permitido a visita quando a mesma utilizar roupas curtas ou transparentes, shorts, bermudas e saias acima do joelho, regatas, blusas curtas ou justas, meia-calça, sutiã com enchimento ou armação, perucas, apliques, joias, bijuterias, chapéus, bonés, toucas, cintos e outros adereços que possam ser utilizados como recurso para alguma atitude violenta e perigosa.

Dentre essas 48 mulheres, encontram-se mães, irmãs, esposas e companheiras. Tendo em vista o assunto do presente artigo, focou-se o estudo nas mulheres que são companheiras ou esposas. Das 22 mulheres que foram abordadas para a realização da pesquisa, apenas seis aceitaram contribuir. Salienta-se que, exceto a primeira entrevistada que possui 41 anos, as demais estão na faixa etária compreendida entre 20 e 24 anos. 
Esteve-se ao lado dessas mulheres durante pouco mais de três horas, até entrarem na prisão. Foi tempo suficiente para perceber que nesse contexto há histórias, dores e, acima de tudo, há mulheres dignas de visibilidade, reconhecimento e respeito. No entanto, trata-se de tema complexo em instituição na qual o silêncio é regra. Assim, embora em outras oportunidades os pesquisadores tenham recebido a informação de que os presos pagam uma taxa "motel" para a prefeitura, nestas entrevistas tal fato não foi aventado.

A primeira entrevistada informou que o marido está preso no Pavilhão A e realiza visitas ao menos duas vezes por semana. É faxineira e o dinheiro de três faxinas por mês reserva para levar ao marido. "Moça, cada galeria tem o seu mercadinho. Só que as coisas são muito caras. Para você ter uma ideia: um refri custa 15 reais". Questiona-se se ela acha importante a visita íntima e ela diz que "Não é fácil para quem está lá dentro e também não é fácil pra quem está do lado de fora. É arrependimento lá dentro e sofrimento aqui fora. Sofremos para estar aqui e dar apoio para eles. Temos de ser fortes por nós e por eles. Passamos por inúmeras situações, discriminações e somos tratadas de forma vergonhosa pelas próprias mulheres da Brigada que realizam a nossa revista. Tudo isso por eles, para passarmos ao menos algumas horas juntos".

A entrevistada chora, lembrando dos momentos que compartilharam juntos e, principalmente, de tudo que ela está vivenciando aqui fora. É um choro de exaustão, física e psicológica, que não merece ser ignorado apenas por estar no contexto prisional. Compartilha-se da tristeza dela, momento que a pesquisadora chora junto, perguntando se pode dar um abraço ${ }^{2}$. Após minutos de silêncio, em um breve abraço, ela reforça que "as pessoas no geral, nos tratam como animais. Eles acham que somos pessoas perigosas e ruins. Que não temos sentimento e que vivemos o tempo todo em contato com o crime. Somos pessoas rejeitadas. Só consigo trabalhar como faxineira, se a patroa não ficar sabendo que meu marido é presidiário". É o estigma.

Enquanto o estranho está à nossa frente, podem surgir evidências de que ele tem um atributo que o torna diferente de outros que se encontram numa categoria em que pudesse ser - incluído, sendo, até, de uma espécie menos desejável - num caso extremo, uma pessoa completamente má, perigosa ou fraca. Assim, deixamos de considerá-lo criatura comum e total, reduzindo-o a uma pessoa estragada e diminuída. Tal característica é um estigma, especialmente quando o seu efeito de descrédito é muito grande - algumas vezes ele também é considerado um defeito, uma fraqueza, uma desvantagem - e constitui uma discrepância específica entre a identidade social virtual e a identidade social real. [...] (GOFFMAN, 1998, p. 12).

\footnotetext{
${ }^{2}$ Isso acontece depois do primeiro de março, quando se divulga o polêmico abraço do médico Drauzio Varella, mas antes do fato ter tomado repercussão nacional. Tampouco a pesquisadora perguntou a razão do marido da informante estar preso.
} 
Difícil ignorar a estigmatização dessas mulheres, pois a prisão é o símbolo de uma grande segregação social. Pode-se, inclusive, dizer que, na atual circunstância, ela se torna uma forma de vingança imposta pelo Estado.

O estigma extrapola os muros prisionais e carrega valores e preconceitos difíceis de remover da vida dos atingidos. Reforçando a explicação, Redígolo (2012, p. 88) menciona:

O estigma é útil socialmente, serve para reafirmar os padrões de normalidade e garantir um controle social. Para que o homem viva em coletividade, ele precisa criar uma série de regras, explicitas ou tácitas, e quem foge a estas regras tem que ser demarcado, separado e controlado, para que a regra se mantenha.

A segunda entrevistada tem 24 anos e há dois meses realiza as visitas ao menos uma vez por semana. Deixa claro que ainda não se acostumou com a cadeia: "Conto os minutos para sair daqui. Não gosto de realizar as visitas. Mas, sei que para ele é importante. Sou a única pessoa que entra na cadeia para ver ele. Se eu não venho, ele fica maluco aí dentro. Não posso abandonar ele assim".

Outra moça da fila que estava ouvindo a nossa conversa disse "Hoje é o meu primeiro dia de visita. Dormi por duas noites aqui na frente do Central, na rua, para conseguir fazer a carteirinha ${ }^{3}$ e visitar ele". Imediatamente, ela vira a terceira entrevistada do dia. Relata que dormiu na rua para conseguir visitar o homem que entrou na sua vida apenas há quatro meses.

Com os olhos marejados, diz: "Estou louca para ver ele. Só vi na triagem e ele estava muito machucado. Ele nem imagina que estou aqui”. Conta que apesar de estarem juntos há pouco, se conhecem desde o ensino fundamental.

A quarta e quinta entrevistadas já realizam visitas íntimas duas vezes na semana há dois anos. Ambas com 20 anos de idade, sem filhos, reforçam que são tratadas "feito lixo" na hora da revista. Uma delas fala que mencionou ao companheiro não quer mais essa vida, nem para ele, nem para ela.

A sexta mulher entrevistada tem 23 anos, frequenta o ambiente há seis anos, e está com o marido há nove anos. Tem uma filha de dois anos e alega ter engravidado dentro da prisão. Quando indagada se considera importante a visita íntima responde: "Claro. Eu sinto que sou muito importante para ele. Eu e nossa filha somos a força dele”. Ela conta que nesses anos todos eles brigaram bastante. Porém, o máximo de tempo que ela conseguiu ficar sem visitar ele foi

\footnotetext{
${ }^{3}$ A "carteirinha" mencionada é documento obrigatório e exigido pela instituição prisional para conseguir realizar as visitas. Para tanto, precisa ser apresentado documento comprovando a União Estável ou Certidão de Casamento.
} 
pelo período de apenas dois meses. "Ele me encheu o saco. Como castigo, já que sou a única pessoa que visita ele, deixei de fazer visitas durante dois meses".

Com relação a visita íntima, as seis mulheres são unânimes em afirmar que é algo extremamente importante e transcende o sexo. Visto que, elas são o alicerce deles nessa jornada. Companheiras que dividem preocupações, que são fonte de carinho e que acabam sendo o único contato com o mundo externo. Zelam pelo bem-estar levando para eles roupas e utensílios de higiene pessoal. Assim, cumprindo com o papel de racionalizar a dinâmica informal da vida prisional e evitando ainda mais a precarização das condições prisionais.

Percebe-se que a fila aumenta bastante e verifica-se um total de 87 mulheres entre mães, irmãs, companheiras e esposas. Continua-se na fila, ao lado delas, e informa-se a permanência até sua entrada. "Vai demorar ainda moça. O horário de visita começa às 7 h30, mas só entraremos por volta das $9 \mathrm{~h}$ horas. Isso que chegamos antes das $6 \mathrm{~h}$ horas aqui. É fila para tudo! Fila aqui fora e mais fila lá dentro".

Aproveita-se o tempo para saber mais sobre o assunto da pesquisa. Surge a informação de que cada galeria tem o seu regramento, o qual é definido pela "prefeitura". Reforçando a informação de Bassani (2016, p. 142-143):

No caso da visita íntima, a ausência de estrutura institucional para a efetivação dos direitos e a necessidade de minimizar a tensão levou o Estado a um menos governo, permitindo a criação de uma homeostase interna. Nestas estratégias, percebe-se o interesse governamental em manter a "prisão calma", ou ao menos impedir que seus problemas extrapolem para fora de seus muros. Neste sentido, o sexo estabelecido pela visita íntima aparece como interessante apelo, envolvendo os presos em atividades voltadas à organização de uma sociedade interna.

A sexta entrevistada informa que consegue ficar com o marido dela o dia todo na cela, pois ele faz parte da "prefeitura". Explica que, via de regra, o momento a dois ocorre por revezamento de uma hora por casal, mas há quem seja privilegiado. Nas demais horas de visitação, juntos, ficam sentados ou deitados no colchão nos corredores ou caminhando pelo pátio.

Uma das regras determina que as mulheres, mesmo no intenso verão, quando estão no corredor com seus respectivos companheiros e maridos, não podem deitar sem cobrir seus corpos, justamente para evitar olhares e brigas entre os presos.

A conversa prossegue e uma delas fala sobre uma rebelião. A entrevistada informa que no seu primeiro dia de visita, há dois anos, enquanto estava em momento íntimo com seu namorado, houve um conflito entre os presos da segunda e terceira galerias, que são de facções 
opostas. Ela conta: "Foi o dia mais horrível da minha vida. Achei que fosse morrer. Alguém deixou os portões abertos e o pessoal da galeria de cima fez de tudo para invadir. Foi um desespero só".

Continua, "Estávamos deitados quando ouvimos barulhos e gritarias. Colocaram todas as visitas nas últimas celas e foram impedir a entrada do pessoal da outra galeria. Empurraram os portões, colocaram fogo nos colchões para impedir a passagem. Se eles tivessem entrado, estaríamos todos mortos. Lá dentro, nada é previsível e não existe segurança".

Quanto ao sexo, pergunta-se para as participantes se a vontade aumenta pelo fato de estarem com seus respectivos companheiros e maridos apenas algumas horas de determinados dias da semana. De forma unânime, todas respondem que a saudade aumenta, contudo o sexo não se torna prazeroso pelo fato do local não ajudar. Uma das entrevistadas, respondendo por todas, menciona: "Não temos muita privacidade, o local é sujo, desconfortável e com cheiro ruim. Sentimos saudade, sentimos falta, sentimos vontade só até entrar lá dentro. Depois, o sexo se torna quase que uma obrigação".

Nesse sentido, observa-se que a visita social e conjugal é uma forma de manter vínculos de afeto e não apenas sexual, fortalecendo laços que podem experimentar aspectos de aprofundamento e compromisso. Para o público prisional masculino, o sexo se torna algo ainda mais desejado e importante, pois dentro do sistema prisional há um conjunto de práticas que infantiliza o ser humano, reduz sua autodeterminação, o despoja de sua masculinidade, empobrece e envilece (Feaux(1991, p. 673); Fragoso (1980, p. 763);Thompson (1998, p. 58) e Pimentel (1979, p. 76)).

A sexta entrevistada relata que, "Com o tempo, acabei me acostumando. É preciso muita concentração para conseguir gozar.”. Se, para as mulheres, o sexo dentro do contexto prisional não se torna agradável, é possível observar que, para os homens, se torna algo necessário. "Lá dentro eles ficam bem loucos e tarados", diz uma das entrevistadas.

Por se tratar de um ambiente que priva a liberdade do indivíduo de muitas formas, o sexo é visto como algo necessário e prazeroso do ponto de vista masculino. Além do mais, foi possível observar que "a questão sexual nas prisões é tema complexo e controverso" (Rudnicki e Santos, 2015, p. 322). Bassani (2016, p. 28-29) menciona:

Do lado de dentro das grades, os atendimentos com os homens traziam informações inusitadas. Falavam da importância da família e, em especial, da companheira no cumprimento da pena, ao qual referiam como "meu pessoal". O "meu pessoal" era o ponto de apoio, o suporte, a alegria rara de uma trajetória sempre mais longa, perigosa e cinza que qualquer um pensara quando cometera o delito. 
Assim, o contato com as mulheres na fila oportuniza averiguar a real importância da visita e das relações decorrentes dela. A persistência das visitantes compromete a afirmação de que a prisão é apenas local de dor, violência e sentimentos ruins. Observa-se que o sistema prisional provoca sérios efeitos colaterais, adversos e complexos, no indivíduo e na vida dele. Baratta (2011, p. 184) explica:

As cerimônias de degradação no início da detenção, com as quais o encarcerado é despojado até dos símbolos exteriores da própria autonomia (vestuários e objetos pessoais), são o oposto de tudo isso. A educação promove o sentimento de liberdade e de espontaneidade do indivíduo: a vida no cárcere, como universo disciplinar, tem um caráter repressivo e uniformizante.

O ingresso da pessoa na prisão irá expô-la a situações muito diferentes da vida cotidiana. Por exemplo, na sua chegada, a pessoa recebe uma nova identificação contendo o número de sua matrícula, o número do artigo infringido no código penal ou um apelido decorrente de alguma peculiaridade das circunstâncias da prisão. Mas, para muitos, há a felicidade de contar com a amizade e o companheirismo da pessoa amada através da visita (íntima), reforçando a ideia da necessidade de comunicação e não exclusão do apenado e a importância de manter contato com o mundo externo. Rudnicki e Veeck (2018, p.72) escrevem:

Nesse sentido, vemos que a carência de informação e comunicação nas penitenciárias consolida barreiras para a ressocialização de quem lá vive, pois não permite a integração de informações básicas, cotidianas e corriqueiras da sociedade externa à prisão, restando seu vínculo restrito à sociedade carcerária.

Por fim, ressalta-se que o espaço repressivo, nada atrativo e de extremo controle, como a prisão, pode não ser o local mais favorável para as relações sexuais, no entanto, consegue-se vislumbrar sentimentos de força, afetos, resiliência, relações que merecem a preservação e direitos dignos de resguardo.

\section{Conclusão}

Acerca do tema proposto, observa-se que há de forma persistente celeumas que até o presente momento necessitam ser tratados quando o assunto é a sexualidade. Verifica-se que o conteúdo ainda gera desconforto para uma parcela da sociedade. Portanto, o objetivo foi abordar a questão da visita íntima e reforçar a necessidade de discussão sobre a sexualidade. Para tal, o caminho que se utilizou para adentrar no assunto foi através de entrevistas com as visitantes que, 
devido ao tema, foram restringidas apenas para esposas e companheiras que estavam na fila de visitas e que aceitaram participar.

Houve menção e reflexão da legislação vigente no País, bem como, no estado do Rio Grande do Sul, acerca do tema visita íntima e de que forma se dá a aplicação dela no contexto. Compreende-se que o direito de visita íntima e, também, o direito ao sexo aparecem como princípio fundamental ao indivíduo. A luta pelo reconhecimento do direito sexual tem uma conotação muito mais ampla, não restringindo apenas o sexo, reforçando a ideia que a dignidade da pessoa humana deve ser respeitada partindo do pressuposto do mínimo existencial.

Há necessidade de se enxergar o apenado como indivíduo possuidor de direitos, respeitando aquilo que ele deseja para si, e com isso reforçar a sua identidade sexual, de forma saudável, afastando qualquer tipo de expectativa social, baseada apenas em um olhar frio e distante do ser humano. Portanto, os pensamentos retrógrados e conformistas não devem imperar, pois a força da lei determina que todos devem ser tratados com isonomia e com dignidade.

Cabe ressaltar que as visitantes são mulheres importantes para o contexto, contribuindo no auxílio de um ambiente mais calmo dentro da prisão, suprindo elementos básicos que o Estado não tem como ofertar.

Portanto, verifica-se a necessidade de uma reflexão por parte da sociedade sobre a visita íntima como um direito extremamente imprescindível. Está claro, através das entrevistas realizadas com as visitantes, a importância dessas mulheres, que são merecedoras de respeito e reconhecimento.

Todas as entrevistadas concordam que, devido ao local ser sujo, com cheiro ruim e nada receptivo, o sexo acaba não se tornando prazeroso para elas. No que tange aos homens, elas afirmam que mesmo nessas condições, o sexo é algo muito desejado.

De toda forma, considerando a atual perspectiva, mais do que nunca, se faz necessário abordar o tema como o intuito de refletir e discutir a necessidade de reconhecer o direito ao sexo dentro do sistema prisional e, também, assegurar o direito de visita íntima. Com condições dignas, visando garantir o respeito à pessoa e seus direitos.

\section{Referências}

AYMARD, Nadia; LHUILIER, Dominique. L'Univers Pénitenciaire: du côté des surveillants de prison. Paris: Desclée de Brouwer, 1997. 
BARATTA, Alessandro. Criminologia Crítica e Crítica do Direito Penal: introdução à sociologia do direito penal. 6a . Edição. Rio de Janeiro: Revan, 2011.

BASSANI, Fernanda. Visita íntima: sexo, crime e negócios na prisão. Porto Alegre: Bestiário, 2016.

BRITTO, Lemos. A Questão Sexual nas Prisões. Rio de Janeiro: Jacintho, 1934.

CAMARGO, Shelley Arruda Pinhal de; SAMPAIO NETO, Luiz Ferraz de. Sexualidade e gênero. Revista da Faculdade de Ciências Médicas de Sorocaba, Sorocaba, v. 19, n. 4, p. 165166, jan. 2018. Disponível em: https://revistas.pucsp.br/RFCMS/article/view/35351 . Acesso em: 18 fev. 2020.

D’ANGELO, Luísa Bertrami; HERNÁNDEZ, Jimena de Garay. Sexualidade, um direito (secundário)? Atravessamentos entre sexualidade, socioeducação e punição. Plural, v. 24, n. 1, p. 78-104, Rio de janeiro. ago. 2017. Disponível em: https://doi.org/10.11606/issn.21768099.pcso.2017.125958. Acesso em: 19 de fev. 2020.

FEAUX, Valmy. La culture em milieu carceral - introduction. Actes de colloque organisé à Nivelles. Revue de Droit Penal et Criminologie, Bruxelas, p. 673-76, jul. 1991.

FRAGOSO, Heleno Cláudio. Perda da liberdade - os direitos dos presos. In: VIII Conferência Nacional da Ordem dos Advogados do Brasil, 8, 1980, Manaus. Anais... Manaus: OAB, 1980, 1.023 p., p. 759-88.

FOUCAULT, Michel. História da sexualidade 1: A vontade de saber. $8^{\mathrm{a}}$. ed. Rio de Janeiro/São Paulo: Paz e Terra, 2019.

FOUCAULT, Michel. Vigiar e punir: Nascimento da prisão; 42 ed. Petrópolis, Rio de Janeiro: Vozes, 2014.

GELPI, João Baptista. Pankrác ECII: crônicas do cárcere de Praga. São Paulo: Tâmisa, 2000. $272 \mathrm{p}$.

GOFFMAN, Erving. Estigma: notas sobre a manipulação de identidade deteriorada. 4. ed. Rio de Janeiro: LTC, 1988.

LAGO, Clenio; TAROUCO, Sabryna Joane Voos Bortoncello; SILVA JUNIOR, Edinaldo Enoque da. A sexualidade no horizonte do discurso. Reflexão e Ação, Santa Cruz do Sul, v. 24, n. $1, \quad$ p. 309-328, abr. 2016. Disponível em: https://online.unisc.br/seer/index.php/reflex/article/view/4380. Acesso em: 20 de fev. 2020. LÉVI-STRAUSS, Claude. Tristes trópicos. São Paulo: Companhia das Letras, 1996 
MORAES, Pedro Rodolfo Bodê de. Punição, encarceramento e construção de identidade profissional entre agentes penitenciários. São Paulo, IBCCRIM, 2005.

PIMENTEL, Manuel Pedro. Sistemas penitenciários. Revista dos Tribunais, São Paulo, 639: 265-74, jan. 1989.

QUEIROZ, Nana. Presos que menstruam. 11ª Edição, Rio de Janeiro: Record, 2019.

REDÍGOLO, Natália Carolina Narciso. Sistema penitenciário e seus estigmas: o caso Paulista. Revista do Laboratório de Estudos da Violência da UNESP/Marília. Edição 9, p. 82-96, maio 2012.

RUDNICKI, Dani; SANTOS, Carla Cristiane Dias dos. Percepções sobre o direito de visita no Presídio Central de Porto Alegre. Revista Brasileira de Ciências Criminais, vol. 115, ano 23, p. 311-333. São Paulo: Ed. RT, jul-ago. 2015.

RUDNICKI, Dani; SCHÄFER, Gilberto; SILVA, Joana Coelho da. As máculas da prisão: estigma e discriminação das agentes penitenciárias. Revista Direito $G V$, São Paulo, v. 13, n. 2, p. 608-627, jul. 2017. ISSN 2317-6172. Disponível em: https://doi.org/10.1590/2317-6172201724 . Acesso em 28 de fev. de 2020.

RUDNICKI, Dani; VEECK, Matheus O. (2018). Sobre o direito à comunicação e o acesso dos presos à internet. Revista Brasileira De Sociologia Do Direito, 5(2). Disponível em: https://doi.org/10.21910/rbsd.v5n2.2018.206 . Acesso em 19 de março de 2020.

SOUZA, Percival de. A prisão. Histórias dos homens que vivem no maior presído do mundo. $2^{\mathrm{a}}$. ed. São Paulo: Alfa-Omega, 1978.

THOMPSON, Augusto. A questão Penitenciária. 4ª Edição, Rio de Janeiro: Forense, 1998. 